\title{
A serosurvey of selected cystogenic coccidia in Spanish equids: first detection of anti-Besnoitia spp. specific antibodies in Europe
}

Daniel Gutiérrez-Expósito ${ }^{1}$, Ignacio García-Bocanegra², Daniel K. Howe³, Antonio Arenas-Montes², Michelle R. Yeargan ${ }^{3}$, SallyAnne L. Ness ${ }^{4}$, Luis M. Ortega-Mora ${ }^{1}$ and G. Álvarez-García ${ }^{1 *}$

\begin{abstract}
Background: Equine besnoitiosis, caused by Besnoitia bennetti, and equine protozoal myeloencephalitis (EPM), caused by Sarcocystis neurona and Neospora hughesi are relevant equine diseases in the Americas that have been scarcely studied in Europe. Thus, a serosurvey of these cystogenic coccidia was carried out in Southern Spain. A cross-sectional study was performed and serum samples from horses $(n=553)$, donkeys $(n=85)$ and mules $(n=83)$ were included. An in-house enzyme-linked immunosorbent assay (ELISA) was employed to identify a Besnoitia spp. infection and positive results were confirmed by an a posteriori western blot. For Neospora spp. and Sarcocystis spp., infections were detected using in-house ELISAs based on the parasite surface antigens N. hughesi rNhSAG1 and S. neurona rSnSAG2/3/4. Risk factors associated with these protozoan infections were also investigated.

Results: Antibodies against Besnoitia spp., Neospora spp. and Sarcocystis spp. infections were detected in 51 (7.1\%), 46 (6.4\%) and 20 (2.8\%) of 721 equids, respectively. The principal risk factors associated with a higher seroprevalence of Besnoitia spp. were the host species (mule or donkey), the absence of shelter and the absence of a rodent control programme. The presence of rodents was the only risk factor for Neospora spp. infection.

Conclusions: This study was the first extensive serosurvey of Besnoitia spp. infection in European equids accomplished by two complementary tests and gives evidence of the presence of specific antibodies in these populations. However, the origin of the infection is still unclear. Further parasite detection and molecular genotyping are needed to identify the causative Besnoitia and Neospora species. Finally, cross-reactions with antibodies directed against other species of Sarcocystis might explain the positive reactions against the S. neurona antigens.
\end{abstract}

Keywords: Besnoitia spp., Sarcocystis spp., Neospora spp., Spain, Serosurvey, Horse, Donkey, Mule, Risk factors

\section{Background}

Cystogenic coccidia such as Sarcocystis spp., Neospora spp., and Besnoitia spp. have been reported to affect equids. Sarcocystis neurona and Neospora hughesi are the causative agents of equine protozoal myeloencephalitis (EPM), a serious neurological disease of horses in the Americas [1]. Moreover, besnoitiosis in donkeys caused by

\footnotetext{
* Correspondence: gemaga@vet.ucm.es; gemaga@ucm.es

'SALUVET, Animal Health Department, Faculty of Veterinary Sciences, Complutense University of Madrid, Ciudad Universitaria s/n, 28040 Madrid, Spain

Full list of author information is available at the end of the article
}

Besnoitia bennetti in donkeys is an emerging disease in the United States [2].

Several serosurveys of Sarcocystis spp. and/or Neospora spp. infections have been carried out in horses and donkeys in Europe (France, Italy, Czech Republic, Sweden and Spain) [3, 4]. However, Besnoitia spp. infection has not been studied in depth in European equids apart from only two reports of equine besnoitiosis. The first case of besnoitiosis in a horse was reported in Northern France [5]. Recently, the disease was suspected in seven donkeys from Southern Spain since tissue cysts were detected by histopathology [6]. Apart from B. bennetti, two additional 
Besnoitia species (B. besnoiti and B. tarandi) also affect ungulates (i.e., bovines and cervidae) causing similar clinical signs and have been reported in Europe [7]. Besnoitiosis caused by $B$. tarandi has been documented in reindeer in the Artic regions [8], whereas besnoitiosis caused by $B$. besnoiti is a re-emergent cattle disease in western and Central Europe and has also been recently reported in roe deer and red deer in Spain [9-11].

Diagnostic tools that provide an accurate serological diagnosis of cystogenic coccidia infections must overcome cross-reactions. Particularly in equids, N. hughesi crossreacts with $N$. caninum [12]. In addition, cross-reactions between anti- $B$. bennetti antibodies and $B$. besnoiti antigens have also been observed [13]. Thus, highly sensitive and specific tests are mandatory in order to confirm an infection. Enzyme-linked immunosorbent assays (ELISAs)-based on recombinant proteins provide an accurate diagnosis of $S$. neurona and $N$. hughesi infection $[14,15]$. A B. besnoiti tachyzoite extract-based ELISA is a routinely employed screening technique for Besnoitia spp. infection and a western blot is used as a confirmatory test in various ungulate species $[2,16]$. In addition, a novel ELISA based on the enrichment of specific antigens has been demonstrated to be highly specific for the diagnosis of bovine besnoitiosis [17].

The goal of the present work was to determine the presence of specific antibodies against Besnoitia spp., Neospora spp. and Sarcocystis spp. in horses, donkeys and mules from southern Spain (Andalusia). This was the first serosurvey of Besnoitia spp. infection in European equids. Moreover, the first results of anti-Neospora spp. antibodies detection in Spanish equids are presented.

\section{Methods}

\section{Sampled areas and experimental design}

A cross-sectional study was carried out between January and March of 2010 in equine herds from Andalusia (southern Spain; $36^{\circ} \mathrm{N}-38^{\circ} 60^{\prime} \mathrm{N}, 1^{\circ} 75^{\prime} \mathrm{W}-7^{\circ} 25^{\prime}$ $\mathrm{W})$, which is the Spanish region with the largest number of equines (see the discussion section).

A total of 721 samples from horses $(n=553)$, donkeys $(n=85)$ and mules $(n=83)$ were included. Specifically, samples from 616 horses were collected in a survey stratified by census tract. We used a convenience sampling technique to select the remaining samples. Horse samples were distributed across all provinces of Andalusia, whereas the donkey and mule samples were restricted to Cádiz Province (Fig. 1). ELISAs based on $S$. neurona and $N$. hughesi recombinant proteins were employed for the detection of anti-Sarcocystis spp. and anti-Neospora spp. antibodies. To detect anti-Besnoitia spp. antibodies, all serum samples were initially screened by a soluble extract-based ELISA, and positive results were confirmed by western blot. Animals seropositive according to the western blot were included in the data analysis.

\section{Samples and data collection}

Blood samples were collected by puncturing of the jugular vein using a sterile collection system (Vacutainer Becton, Dickinson and Company, USA). Next, the blood samples were centrifuged at $400 \mathrm{~g}$ for $15 \mathrm{~min}$ at $4{ }^{\circ} \mathrm{C}$ and the sera were separated and stored at $-20{ }^{\circ} \mathrm{C}$ until further analysis.

Epidemiological data were collected by an on-farm interview with the owners (Additional file 1), who were informed of the goals of the study. The questionnaires were especially designed to collect information using "closeended" questions to avoid ambiguous or lengthy answers. In total, 18 explanatory variables were included in the analysis: species (horse, mule and donkey), age classes (young: $<5$ years, adult: $5-16$ years and geriatric: $>16$ years), gender (male and female), colour (dark and light), breed (Spanish, Arabian, Spanish-Arabian, other purebred and crossbred), province, activity (farming, leisure and work), type of housing (outside and individual or collective shelter), direct contact with other horses, mules or donkeys, presence of other animal species (domestic and wild birds, domestic and wild ruminants), presence of rodents, insecticide treatment, cleaning and disinfection methods and protocols, pest control programmes (insects and rodents) and water sources. The sero-status of any animals that shared the same habitat as the sampled equids was unknown.

\section{Antigen production for serological tests}

Culture-derived tachyzoites of $B$. besnoiti isolate -Bb-Spain 1 [18] were propagated and purified [19] to prepare antigens for the ELISA and western blot tests. Foetal bovine serum was previously checked for the absence of anti-Besnoitia, anti-N. caninum and anti-T. gondii antibodies by an immunofluoresce antibody test (IFAT) [18]. Soluble B. besnoiti tachyzoite antigens used in the ELISA were prepared and quantified as previously described [20] and maintained at $-80{ }^{\circ} \mathrm{C}$ until use. Besnoitia besnoiti tachyzoites were pelleted and frozen at $-80{ }^{\circ} \mathrm{C}$ for western blot.

Sarcocystis neurona and $N$. hughesi recombinant proteins were purified as described previously [14, 15] and maintained at $4{ }^{\circ} \mathrm{C}$ until use.

\section{Serology}

ELISAs Besnoitia besnoiti tachyzoite soluble extract was used as antigens because strong cross-reactions were present between $B$. besnoiti antigens and anti-B. bennetti specific antibodies as indicated by IFAT and western blot [13]. Serum samples were analysed in duplicate, as 


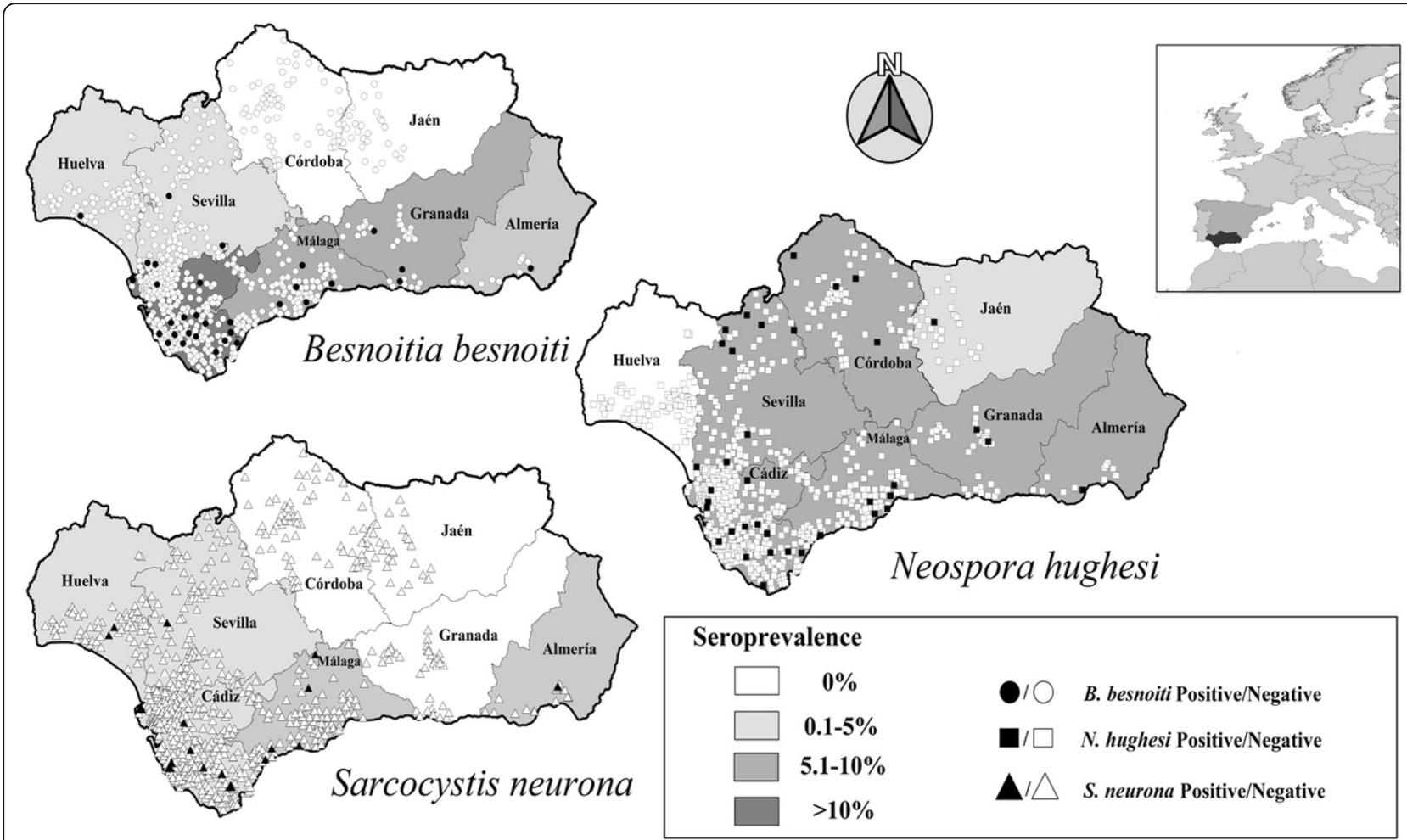

Fig. 1 Geographical distribution of equids sampled in Andalusia and seropositive results to B. besnoiti, N. hughesi and S. neurona infections. Positive results are marked in black and negative results are marked in white. Prevalence of infection by province is represented in grey

previously described [21], with a few modifications: (i) a blocking solution of phosphate buffered saline (PBS) containing $0.05 \%$ Tween 20 and $3 \%$ bovine serum albumin (Roche ${ }^{\circ}$ was used, and (ii) a rabbit peroxidaselabelled anti-horse $\operatorname{IgG}(\mathrm{H}+\mathrm{L})$ antibody conjugate $\left(\right.$ INGENASA $\left.^{\circ}\right)$ diluted at 1:5000 was used. The cut-off value was selected on the basis of three standard deviations of optical density (OD) values obtained with a panel of seronegative horse samples $(n=20)$. Positive and negative control sera tested by western blot consisted of chronically infected donkeys [13] and noninfected horses from USA and Spain, respectively. A cut-off at OD values higher than 0.40 was established and ELISA-positive results were confirmed by a western blot (Fig. 2).

Anti-Neospora spp. and anti-Sarcocystis spp. antibodies were detected using the recombinant $N$. hughesi surface antigen rNhSAG1 and $S$. neurona trivalent protein rSnSAG2/4/3 by means of previously described ELISAs $[14,15]$. Percent positivity (PP) values of 20 and 15 were used as cut-offs for $N$. hughesi and $S$. neurona antigenbased ELISAs, respectively. The horse positive control serum employed in the Neospora spp.-based ELISA came from a mare that was experimentally infected during pregnancy with $N$. hughesi. The horse positive control serum for the Sarcocystis spp.-based ELISA was collected from two clinically affected horses with confirmed EPM by histopathology. The negative control serum for both ELISAs consisted of a serum collected from a weanling prior to infection with $S$. neurona [22]. This serum was negative by $S$. neurona-, T. gondii-, N. caninum-, and $N$. hughesi- based western blots.

\section{SDS-PAGE and western blot}

A total of $4 \times 10^{7}$ tachyzoites under non-reducing conditions were employed for the electrophoresis of $B$. besnoiti [23]. Tachyzoite antigens were transferred to a nitrocellulose membrane and, incubated with sera from either horses, donkeys or mules at a 1:20 dilution, followed by a peroxidase-conjugated anti-horse IgG $(\mathrm{H}+\mathrm{L})$ antibody diluted at 1:500 (INGENASA ${ }^{\circ}$, Madrid, Spain). Control sera were the same as used for the ELISA. The presence of at least three bands in at least two of the three principal antigenic areas (area I: 72.5, 58.9 and $51.4 \mathrm{kDa}$; area II: 38.7 , 31.8 and $28.5 \mathrm{kDa}$; area III: 23.6, 19.1, 17.4, $14.5 \mathrm{kDa}$ ) was considered as a positive result for a Besnoitia spp. infection (Fig. 2) [23].

\section{Statistical analysis}

The prevalence of antibodies against Besnoitia spp., Neospora spp. and Sarcocystis spp. infections was 


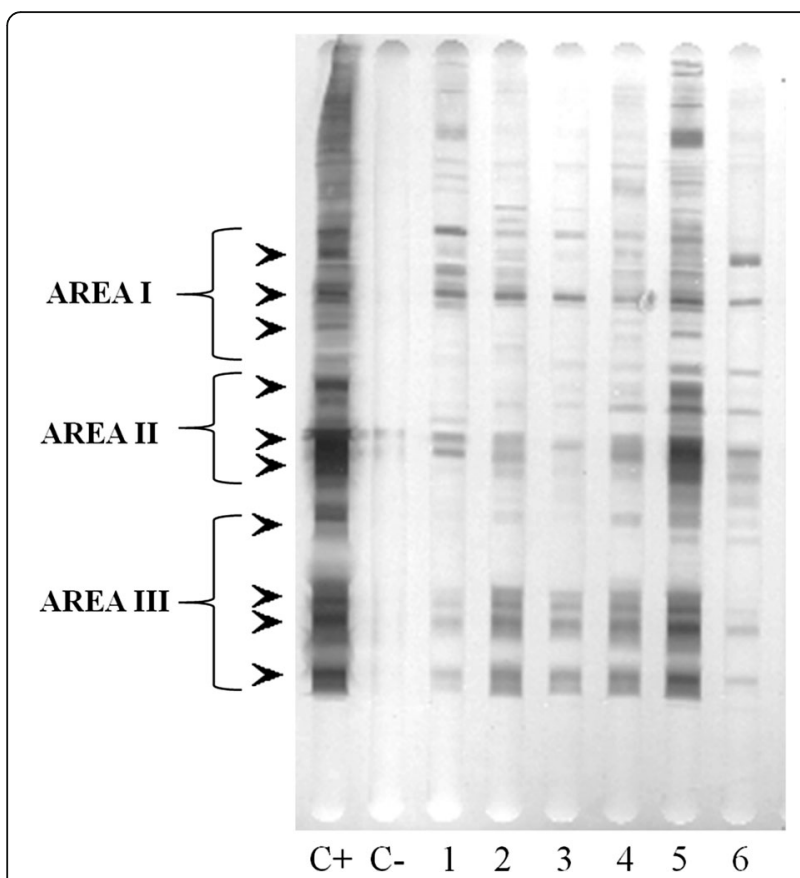

Fig. 2 Recognition of Besnoitia spp. tachyzoite antigens by western blot. Lines 1-6: samples from Besnoitia spp. ELISA seropositive equids. Arrows indicate recognition of antigenic bands in each of the three principal antigenic areas

estimated with the exact binomial confidence intervals of $95 \%$ [24].

To detect non-linear relationships and to homogenize the scales of the explanatory variables, all quantitative variables were transformed to qualitative variables using three categories of the 33rd and 66th percentiles as cutoff values. Tests of association were performed in three steps. First, a general linear univariate analysis was performed. The herd was the experimental unit, and the individual seroprevalence against $B$. besnoiti and $N$. hughesi was the dependent variable. Second, factors showing a $P$-value $<0.15$ were further scrutinized for associations using Spearman's rank correlation coefficient $(r)$ to avoid colinearity problems. When colinearity $(P<0.05$ and $r>0.4)$ was present, only the variable more clearly linked to Besnoitia spp. and Neospora spp. seropositivity was retained. The third step involved a generalized estimating equations model (GEE) [25]. The number of seropositive animals was assumed to follow a binomial distribution and the herd was included as a random effect. A Poisson error distribution and a logit link function were considered.

An initial model was obtained using all of the potential explanatory variables and variables with a non-significant $P$-value were sequentially deleted. The quasi-likelihood under an independence model criterion was used to determine the best model in terms of its potential for explaining the results. Biologically plausible confounding factors were assessed using a Mantel-Haenszel analysis and confounding was considered to be potentially significant if the odds ratios (ORs) were shifted appreciably. Variables that altered the coefficients of the independent variables of interest by $30 \%$ or more when removed from the model were classified as confounding factors. The model was rerun until all of the remaining variables were statistically significant (i.e., the likelihood-ratio via Wald's test had $P<0.05$ ), and a potential causal relationship with the response variable existed. SPSS 22.0 software (SPSS Inc., Chicago, IL, USA) was used for statistical analysis.

The association between Besnoitia spp. ELISA falsepositive results and the presence of anti-Neospora spp. and anti-Sarcocystis spp. antibodies was estimated by using the chi-square test. A Mann-Whitney $U$ test was used to compare differences in the anti-Besnoitia spp. antibody levels estimated by ELISA between the falsepositive and true-positive results. These statistical analyses were performed with the InStat 3.05 software (GraphPad). Additionally, the test agreement expressed as the kappavalues $(k)$ between the ELISA and the western blot tests was calculated using WinEpiscope 2.0 [26].

\section{Results}

\section{Seroprevalence}

Antibodies against Besnoitia spp., Neospora spp. and Sarcocystis spp. were detected in 51 (7.1\%; $\mathrm{Cl}_{95 \%}$ : 5.2-8.9), 46 (6.4\%; $\mathrm{CI}_{95 \%}$ : 4.6-8.2) and $20\left(2.8 \% \mathrm{CI}_{95 \%}: 1.6-4.0\right)$ of 721 equids tested, respectively. Seropositivity against both Besnoitia spp. and Neospora spp. were confirmed in 0.8\% (6/721), against both Besnoitia spp. and Sarcocystis spp. in 0.6\% (4/721) and against both Neospora spp. and Sarcocystis spp. in $0.4 \%$ (3/721) equids (Table 1). A good agreement between the ELISA and the western blot tests was obtained $(k=0.6)$.

\section{Cross-reactions between anti-Besnoitia spp. antibodies and other cystogenic coccidia}

Antibodies against Neospora spp. and/or Sarcocystis spp. were detected in $8.7 \%(63 / 721)$ of the sampled animals (Table 2). Interestingly, true Besnoitia-seropositive animals that were also positive against Neospora spp. and/or Sarcocystis spp. had OD values higher than 0.8 , whereas OD values of false Besnoitia-seropositive animals varied from 0.40 to 0.56 (Table 2) $(P<0.001$, Mann-Whitney $U$ test). However, the existence of Besnoitia spp. falsepositive results was not significantly associated with seropositivity against Neospora spp. or Sarcocystis spp. $(P=0.55)$.

\section{Risk factors}

Due to the low number of Sarcocystis spp. seropositive animals, risk factors were only analysed using Besnoitia 
Table 1 Variables identified as significant $(P<0.15$ in the univariate analysis) and included in the multivariate analysis

\begin{tabular}{|c|c|c|c|c|c|c|}
\hline \multirow[b]{2}{*}{ Variables } & \multirow[b]{2}{*}{ Categories } & \multirow[b]{2}{*}{ No. analyzed ${ }^{a}$} & \multicolumn{2}{|c|}{ Besnoitia besnoiti } & \multicolumn{2}{|c|}{ Neospora hughesi } \\
\hline & & & Positive (\%) & $P$-value & Positive (\%) & $P$-value \\
\hline \multirow[t]{3}{*}{ Species } & Horse & 553 & $16(2.9)$ & $<0.001$ & & \\
\hline & Donkey & 85 & $13(15.3)$ & & & \\
\hline & Mule & 83 & $22(26.5)$ & & & \\
\hline \multirow[t]{2}{*}{ Breed } & Pure & 370 & $18(4.9)$ & 0.005 & $30(8.1)$ & 0.021 \\
\hline & Crossbred & 298 & $31(10.4)$ & & $12(4.0)$ & \\
\hline \multirow[t]{2}{*}{ Sex } & Female & 306 & $26(8.5)$ & 0.129 & & \\
\hline & Male & 415 & $25(6.0)$ & & & \\
\hline \multirow[t]{8}{*}{ Province } & Almeria & 14 & $1(7.1)$ & $<0.001$ & & \\
\hline & Cadiz & 320 & $40(12.5)$ & & & \\
\hline & Córdoba & 60 & $0(0.0)$ & & & \\
\hline & Granada & 38 & $3(7.9)$ & & & \\
\hline & Huelva & 60 & $1(1.7)$ & & & \\
\hline & Jaen & 30 & $0(0.0)$ & & & \\
\hline & Malaga & 98 & $5(5.1)$ & & & \\
\hline & Seville & 101 & $1(1.0)$ & & & \\
\hline \multirow[t]{2}{*}{ Presence of shelters } & Yes & 407 & $15(3.7)$ & $<0.001$ & $23(5.7)$ & 0.122 \\
\hline & No & 280 & $35(12.5)$ & & $23(8.2)$ & \\
\hline \multirow[t]{2}{*}{ Presence of wild birds } & Yes & 403 & $40(9.9)$ & 0.001 & & \\
\hline & No & 275 & $9(3.3)$ & & & \\
\hline \multirow[t]{2}{*}{ Presence of cattle } & Yes & 145 & $19(13.1)$ & 0.020 & $17(11.7)$ & 0.017 \\
\hline & No & 417 & $29(7.0)$ & & $24(5.8)$ & \\
\hline \multirow[t]{2}{*}{ Presence of wild ruminants } & Yes & 41 & & & $8(19.5)$ & 0.006 \\
\hline & No & 521 & & & $33(6.3)$ & \\
\hline \multirow[t]{2}{*}{ Presence of rodents } & Yes & 388 & $35(9.0)$ & 0.001 & $34(8.8)$ & 0.002 \\
\hline & No & 261 & $8(3.1)$ & & $15(5.7)$ & \\
\hline \multirow[t]{2}{*}{ Rodent control program } & Yes & 434 & $24(5.5)$ & 0.009 & & \\
\hline & No & 226 & $25(11.1)$ & & & \\
\hline \multirow[t]{2}{*}{ Cleaning protocol } & Yes & 581 & $38(6.5)$ & 0.018 & $32(5.5)$ & 0.068 \\
\hline & No & 86 & $12(14.0)$ & & $9(10.5)$ & \\
\hline \multirow[t]{2}{*}{ Disinfection protocol } & Yes & 536 & $32(6.0)$ & 0.006 & & \\
\hline & No & 127 & $17(13.4)$ & & & \\
\hline
\end{tabular}

${ }^{a}$ Missing values were omitted

spp. and Neospora spp. seropositive animals as the dependent variables.

Eleven explanatory variables were selected from the univariate analysis for Besnoitia spp. infection $(P<0.15)$ (Table 2). The seroprevalence was significantly higher in mules $(26.5 \%)$ and donkeys (13.3\%) compared to that in horses (2.9\%) (Table 2). The seroprevalence values differed among provinces for horses (Fig. 1) and the seroprevalence was lower in the presence of shelters, whereas it was higher in the presence of rodents (Table 2).

The principal risk factors associated with a Besnoitia spp. infection were species (mule and donkey) $(\mathrm{OR}=12.06$ and $\mathrm{OR}=2.06$, respectively $)$, the absence of shelters $(\mathrm{OR}=2.45)$ and the absence of rodent a control programme $(\mathrm{OR}=5.34)$ (Table 3$)$. The presence of rodents $(\mathrm{OR}=4.83)$ was the only risk factor for a Neospora spp. infection (Table 3 ).

\section{Discussion}

In the present study, we investigated three cystogenic coccidial infections that have been little studied in European equids. In fact, clinical cases of EPM have not been diagnosed in the Old World. Regarding other epidemiological gaps, the definitive hosts of $N$. hughesi and Besnoitia spp. that affect ungulates are still unknown [7, 27]. In contrast, the definitive host of $S$. neurona (Didelphis spp.) appears to 
Table 2 Detection of anti-Besnoitia spp., anti-Sarcocystis spp. and anti-Neospora spp. antibodies by ELISA

\begin{tabular}{llllll}
\hline & $n$ & $\begin{array}{l}\text { Seropositive to } \\
\text { Sarcocystis spp. (\%) }\end{array}$ & $\begin{array}{l}\text { Seropositive to } \\
\text { Neospora spp. (\%) }\end{array}$ & $\begin{array}{l}\text { Seropositive to Sarcocystis } \\
\text { spp. and Neospora spp. (\%) }\end{array}$ & $\begin{array}{l}\text { Seronegative to Sarcocystis } \\
\text { spp. and Neospora spp. (\%) }\end{array}$ \\
\hline $\begin{array}{l}\text { Besnoitia spp. seropositive } \\
\text { Besnoitia spp. seronegative }\end{array}$ & 51 & $4(7.84 \%)$ & $6(11.76 \%)$ & $0(0.0 \%)$ & $41(80.39 \%)$ \\
$\begin{array}{l}\text { Besnoitia spp. seronegative with a } \\
\text { false-positive ELISA result }\end{array}$ & 29 & $2(6.89 \%)$ & $36(5.61 \%)$ & $1(0.15 \%)$ & $593(92.51 \%)$ \\
\begin{tabular}{l} 
Total \\
\hline
\end{tabular} & 721 & $17(2.35 \%)$ & $43(5.96 \%)$ & $3(0.41 \%)$ & $24(82.75 \%)$
\end{tabular}

${ }^{a}$ True Besnoitia-seropositive animals confirmed by western blot

be restricted to the New World, but other species of Sarcocystis are known to infect equids in the Old World [4].

This serosurvey was focused on Andalusia, which has the highest number of equid herds in Spain (44.3\%) [28]. In addition, Besnoitia spp. infections have been reported in cattle and suspected in donkeys from Andalusia [6, 29]. In contrast, no data exist for Neospora spp. and Sarcocystis spp. infections in equids from this region. Thus, the impact of EPM is unknown.

The most relevant finding of this work was the first detection of specific antibodies against Besnoitia spp. in European equids. The diagnostic approach (i.e., an initial screening by ELISA followed by a confirmatory western blot) was previously used in serosurveys conducted in the absence of a panel of reference sera and a gold standard test $[11,16]$ using sera from clinically Besnoitia spp.-infected donkeys as a positive control [13, 23]. Additionally, serological crossreactions with antibodies against Neospora spp. and Sarcocystis spp. were ruled out, probably due to the low antibody levels detected against Neospora spp. and Sarcocystis spp. in this study and the use of highly specific recombinant proteins. Since the Besnoitia ELISA can yield ambiguous results, a western blot or a more specific ELISA are mandatory in order to confirm the infection [17].
Outside of Europe, a few cases of Besnoitia spp. infections in various equid species (horse, donkey, mule and zebra) were attributed to $B$. bennetti infection in the midtwentieth century in different sub-Saharan countries such as South Africa and Sudan [30-32]. It has been suggested that besnoitiosis may be an emerging disease in donkeys in the United States [2]. Furthermore, equine besnoitiosis in Europe was first reported in 1922 [5] in a horse in Northern France. The disease has not been diagnosed since, but in a recent outbreak of donkeys from Southern Spain besnoitiosis was suspected [6]. Seroprevalence rates of Besnoitia spp. infection in other ungulate species of Spain of 1\% (2/2608) and 0\% (0/2285) have been reported in wild and small domestic ruminants, respectively, in areas where bovine besnoitiosis is highly endemic [11, 33]. However, whether equids may be reservoirs or intermediate hosts of $B$. besnoiti should be further elucidated through molecular genotyping [34].

Interestingly, the highest seroprevalence of Besnoitia spp. infection was observed in donkeys and mules. However, a higher susceptibility to Besnoitia spp. infection in donkeys and mules compared to that in horses has not been demonstrated. Most of the clinical cases of equine besnoitiosis have been reported in donkeys $[2,35,36]$. Although less frequently, the disease has also been diagnosed in horses [30,32, 37]. The differences in the

Table 3 Generalized estimating equations model of potential risk factors associated with Besnoitia spp. and Neospora spp. seropositivity

\begin{tabular}{|c|c|c|c|c|c|c|}
\hline Variable & Category & $\beta$ & Sig. & OR & $95 \% \mathrm{Cl}$ & \\
\hline \multicolumn{7}{|l|}{ Besnoitia spp. } \\
\hline \multirow[t]{3}{*}{ Species } & Horse & * & * & * & * & * \\
\hline & Donkey & 0.723 & 0.116 & 2.060 & 0.836 & 5.075 \\
\hline & Mule & 2.490 & $<0.001$ & 12.061 & 3.907 & 37.235 \\
\hline \multirow[t]{2}{*}{ Presence of shelters } & Yes & * & * & * & * & * \\
\hline & No & 0.898 & 0.038 & 2.455 & 1.053 & 5.725 \\
\hline \multirow[t]{2}{*}{ Rodent control program } & Yes & * & * & * & * & * \\
\hline & No & 1.676 & 0.001 & 5.342 & 1.952 & 14.623 \\
\hline \multicolumn{7}{|l|}{ Neospora spp. } \\
\hline \multirow[t]{2}{*}{ Presence of rodents } & Yes & 1.575 & 0.003 & 4.831 & 1.680 & 13.890 \\
\hline & No & * & * & $*$ & $*$ & * \\
\hline
\end{tabular}

* Reference category; OR, Odds ratio; 95\% Cl, 95\% Confidence interval 
management and biosecurity measures between donkeys/mules and horse herds could be a feasible explanation for this finding. Similar to bovine besnoitiosis, parasite transmission might occur through direct contact during natural mating or from bites of blood-sucking arthropods, and animal movement might favour the spread of the disease [29]. Indeed, it was suggested that the use of repellents indoors may help to reduce mechanical transmission by blood-sucking insects [29]. In this study, data on treatment with ectoparasiticides were only recorded in 229 animals and 190 were treated (156 of the treated animals were horses; data not shown). In addition, the absence of shelters would also lead to a higher exposure to blood-sucking arthropods. Finally, whether rodents may act as intermediate hosts of $B$. bennetti as they do for other Besnoitia species ( $B$. akodoni, B. jellisoni, B. neotomofelis and B. wallacei) has not been clarified yet $[7,9]$. The Besnoitia species that parasitize equids must be elucidated. Because $B$. besnoiti and $B$. bennetti infections are serologically indistinguishable, further molecular analyses and parasite isolations are necessary in order to determine which Besnoitia species might be present in Spanish equids.

Antibodies against the aetiological agents of EPM ( $N$. hughesi and $S$. neurona) were also researched in this study. However, the simple detection of a specific antibody does not confirm the diagnosis of the disease since EPM occurs in a small proportion of infected horses [1]. This initial serosurvey of Neospora spp. infection carried out in Spanish equids showed a low seroprevalence (6.4\%) and that the presence of rodents was a risk factor for a Neospora spp. infection. These results agreed with other studies carried out in different European countries such as France, Sweden and Italy that revealed a seroprevalence of approximately $10 \%[3,38,39]$. Little it is known about the role of rodents in the epidemiology of equine neosporosis. Rodents could be considered as a putative intermediate host of equine neosporosis, similarly to bovine neosporosis. In fact, $N$. caninum DNA could be detected in mice and rats in cattle herds with a previous history of neosporosis [40-42]. Equids likely become infected with Neospora spp. via the ingestion of oocysts shed by the definitive host, or possibly through vertical transmission $[43,44]$.

The Neospora species present in these equids remain to be elucidated, since cross-reactions between both existing Neospora species are widely known [12]. Indeed, the rNhSAG1-based ELISA clearly detects antibodies to the $N$. caninum orthologue [14]. In this study, Neospora spp. seropositive sera were demonstrated to be seropositive by $N$. caninum-based western blot, supporting this assumption (see Additional file 2).

Finally, anti-Sarcocystis spp. antibodies were detected in $2.8 \%$ equids and this level is similar to previous reports in
France and northern Spain [45, 46]. Spanish horses are unlikely to be exposed to $S$. neurona due to the absence of the definitive host in Europe but cross-reactions with other species of Sarcocystis might explain positive reactions. In fact, the trivalent rSnSAG surface antigen chimaera-based ELISA was not validated with sera from European equids. Additionally, other latent Sarcocystis spp. cysts are present in equids and are often benign.

\section{Conclusions}

This is the first serosurvey of Besnoitia spp. and Neospora spp. infections carried out in Spain. This study found specific antibodies against Besnoitia spp. infection in European equids. Anti-Neospora spp. and Sarcocystis spp. antibodies were also found in a few animals. However, neither parasitic disease had been not previously diagnosed in Europe. Further parasite detection and molecular genotyping are needed to clarify the presence and identity of these three parasite species [11].

\section{Endnotes}

${ }^{1}$ See: http://www.mapama.gob.es/es/ganaderia/temas/ sanidad-animal-higiene-ganadera/sanidad-animal/enfermedades/fiebre-nilo-occidental/F_O_Nilo.aspx\#para4 (Accessed 25th of April 2017)

\section{Additional files}

Additional file 1: Questionnaire survey developed for use in this study. (DOCX 129 kb)

Additional file 2: Detection of specific anti-Neospora spp. antibodies by a western blot test validated for bovine neosporosis [47]. (DOC 302 kb)

\section{Abbreviations}

B: Besnoitia; ELISA: Enzyme-linked immunosorbent assay; EPM: Equine protozoal myeloencephalitis; GEE: Generalized estimating equation; IFAT: Immunofluorescence antibody test; Ig: Immunoglobulin; k: Kappa value; kDa: Kilodalton; N: Neospora; OD: Optical density; OR: Odd ratio; S: Sarcocystis; SPSS: Statistical package for the social sciences

\section{Acknowledgments}

We would like to thank the Epidemiological Monitoring Program of the Regional Government of Andalusia and farmers for providing the samples. Finally, we also acknowledge Paula García-Lunar, Alejandro JiménezMeléndez and Carlos Diezma-Díaz for their excellent technical assistance.

\section{Funding}

This study was supported by several research projects (AGL 2010-20,561, CYTED Thematic Network 113 RT0469 Protozoovac and by PLATESA S20137ABI-2906). Daniel Gutiérrez Expósito has been financially supported by the Ministry of Science and Innovation (grant no. BES-2011-043753).

\section{Availability of data and materials}

The datasets analysed in the current study are available from the corresponding author upon reasonable request.

\section{Authors' contributions}

DGE performed serological tests against Besnoitia spp. infection, analysed the data and drafted the manuscript; IGB and AAM provided serum samples, carried out the statistical analyses and drafted the manuscript; DKH and MRY performed the ELISA tests against Neospora spp. and Sarcocystis spp. 
infections; SLN provided positive control sera against a Besnoitia spp. infection; LMO and GAG contributed to the conception and design of the study. GAG analysed the data and drafted the manuscript. All authors critically reviewed the manuscript and agreed to the final version.

\section{Competing interests}

All authors declare that they or their institutions have no financial and personal relationship with other people or organizations that could inappropriately influence their work.

\section{Consent for publication}

The manuscript contains no individual person's data and does not require consent for publication.

\section{Ethics approval and consent to participate}

The samples were collected during the control programme of West Nile virus $^{1}$ by the official veterinarians of Andalusia, so no formal ethical approval was necessary. The official veterinarians explained the aim of the survey and obtained verbal consent from the owners prior to the interview.

\section{Publisher's Note}

Springer Nature remains neutral with regard to jurisdictional claims in published maps and institutional affiliations.

\section{Author details}

'SALUVET, Animal Health Department, Faculty of Veterinary Sciences, Complutense University of Madrid, Ciudad Universitaria s/n, 28040 Madrid, Spain. ${ }^{2}$ Animal Health Department, Faculty of Veterinary Sciences, University of Cordoba-Agrifood Excellence International Campus (ceiA3), Cordoba, Spain. ${ }^{3}$ Department of Veterinary Science, M.H. Gluck Equine Research Center, University of Kentucky, Lexington, KY 40546-0099, USA. ${ }^{4}$ Department of Clinical Sciences, College of Veterinary Medicine, Box 52, Cornell University, Ithaca, NY 14853, USA.

Received: 13 February 2017 Accepted: 4 May 2017 Published online: 10 May 2017

\section{References}

1. Howe DK, Mackay RJ, Reed SM. Equine protozoal myeloencephalitis. Vet Clin North Am Equine Pract. 2014;30:659-75

2. Ness SL, Schares G, Peters-Kennedy J, Mittel LD, Dubey JP, Bowman DD Mohammed HO, Divers TJ. Serological diagnosis of Besnoitia bennetti infection in donkeys (Equus asinus). J Vet Diagn Investig. 2014;26:778-82

3. Bártová E, Machacova T, Sedlák K, Budíková M, Mariani U, Veneziano V. Seroprevalence of antibodies of Neospora spp. and Toxoplasma gondii in horses from southern Italy. Folia Parasitol. 2015;62:43.

4. Dubey JP, Howe DK, Furr M, Saville WJ, Marsh AE, Reed SM, Grigg ME. An update on Sarcocystis neurona infections in animals and equine protozoal myeloencephalitis (EPM). Vet Parasitol. 2015;209:1-42.

5. Henry A, Masson G. Globidiose cutanée du cheval. In: Traite de protozoologie médicale et vétérinare. París: Vigot Freres; 1922. p. 386-7.

6. Zafra R, Soria-López N, de Castro ED, Jaber J, Mozos E, Pérez J. Outbreak of besnoitiosis in donkeys (Equus asinus) in the south of Spain. J Comp Pathol. 2013;1:81.

7. Olias P, Schade B, Mehlhorn H. Molecular pathology, taxonomy and epidemiology of Besnoitia species (protozoa: Sarcocystidae). Infect Genet Evol. 2011;11:1564-76.

8. Dubey JP, Sreekumar C, Rosenthal BM, Vianna MC, Nylund M, Nikander S, Oksanen A. Redescription of Besnoitia tarandi (protozoa: Apicomplexa) from the reindeer (Rangifer tarandus). Int J Parasitol. 2004;34:1273-87.

9. EFSA. European food safety authority - bovine Besnoitiosis: an emerging disease in Europe. EFSA J. 2010;8:1499.

10. Arnal M, Gutiérrez-Expósito D, Martínez-Durán D, Regidor-Cerrillo J, Revilla M, Fernández de Luco D, Jiménez-Meléndez A, Ortega-Mora LM, Álvarez-García G. Systemic besnoitiosis in a juvenile roe deer (Capreolus capreolus). Transbound Emerg Dis. 2016; doi: 10.1111/tbed.12514.

11. Gutiérrez-Expósito D, Arnal MC, Martínez-Durán D, Regidor-Cerrillo J, Revilla M, Fernández de Luco D, Jiménez-Meléndez A, Calero-Bernal R, Habela Martínez-Estéllez MA, García-Bocanegra I, Arenas-Montes A, Álvarez-García G. The role of wild ruminants as reservoirs of Besnoitia besnoiti infection in cattle. Vet Parasitol. 2016;223:7-13.
12. Gondim LF, Lindsay DS, MCAllister MM. Canine and bovine Neospora caninum control sera examined for cross-reactivity using Neospora caninum and Neospora hughesi indirect fluorescent antibody tests. J Parasitol. 2009;95:86-8.

13. Ness SL, Peters-Kennedy J, Schares G, Dubey JP, Mittel LD, Mohammed HO, Bowman DD, Felippe MJ, Wade SE, Shultz N, Divers TJ. Investigation of an outbreak of besnoitiosis in donkeys in northeastern Pennsylvania. J Am Vet Med Assoc. 2012;240:1329-37.

14. Hoane JS, Yeargan MR, Stamper S, Saville WJ, Morrow JK, Lindsay DS, Howe DK Recombinant NhSAG1 ELISA: a sensitive and specific assay for detecting antibodies against Neospora hughesi in equine serum. J Parasitol. 2005;91:446-52.

15. Yeargan M, de Assis Rl, Morrow J, Graves A, Reed SM, Howe DK. A new trivalent SnSAG surface antigen chimera for efficient detection of antibodies against Sarcocystis neurona and diagnosis of equine protozoal myeloencephalitis. J Vet Diagn Investig. 2015;27:377-81.

16. Gutiérrez-Expósito D, Ortega-Mora LM, Marco I, Boadella M, Gortázar C, San Miguel-Ayanz JM, García-Lunar P, Lavin S, Álvarez-García G. First serosurvey of Besnoitia spp. infection in wild European ruminants in Spain. Vet Parasitol. 2013;197:557-64.

17. Schares G, Langenmayer MC, Scharr JC, Minke L, Maksimov P, Maksimov A, Schares S, Barwald A, Basso W, Dubey JP, Conraths FJ, Gollnick NS. Novel tools for the diagnosis and differentiation of acute and chronic bovine besnoitiosis. Int J Parasitol. 2013;43:143-54.

18. Fernández-García A, Risco-Castillo V, Pedraza-Díaz S, Aguado-Martínez A, Álvarez-García G, Gómez-Bautista M, Collantes-Fernández E, Ortega-Mora LM. First isolation of Besnoitia besnoiti from a chronically infected cow in Spain. J Parasitol. 2009;95:474-6.

19. Pérez-Zaballos FJ, Ortega-Mora LM, Álvarez-García G, Collantes-Fernández E, Navarro-Lozano V, García-Villada L, Costas E. Adaptation of Neospora caninum isolates to cell-culture changes: an argument in favor of its clonal population structure. J Parasitol. 2005:91:507-10.

20. Álvarez-García G, Pereira-Bueno J, Gómez-Bautista M, Ortega-Mora LM. Pattern of recognition of Neospora caninum tachyzoite antigens by naturally infected pregnant cattle and aborted foetuses. Vet Parasitol. 2002;107:15-27.

21. Fernández-García A, Álvarez-García G, Risco-Castillo V, Aguado-Martínez A, Marcén JM, Rojo-Montejo S, Castillo JA, Ortega-Mora LM. Development and use of an indirect ELISA in an outbreak of bovine besnoitiosis in Spain. Vet Rec. 2010;166:818-22.

22. Fenger CK, Granstrom DE, Gajadhar AA, Williams NM, McCrillis SA, Stamper S, Langemeier JL, Dubey JP. Experimental induction of equine protozoal myeloencephalitis in horses using Sarcocystis sp. Sporocysts from the oposum (Didelphis virginiana). Vet Parasitol. 1997;68:199-213.

23. García-Lunar P, Ortega-Mora LM, Schares G, Gollnick NS, Jacquiet P, Grisez C, Prevot F, Frey CF, Gottstein B, Álvarez-García G. An inter-laboratory comparative study of serological tools employed in the diagnosis of Besnoitia besnoiti infection in bovines. Transbound Emerg Dis. 2013;60:59-68.

24. Thrusfield M, Ortega C, de Blas I, Noordhuizen JP, Frankena K. WIN EPISCOPE 2.0: improved epidemiological software for veterinary medicine. Vet Record. 2001;148:567-72.

25. Hanley JA, Negassa A, Edwardes MD, Forrester JE. Statistical analysis of correlated data using generalized estimating equations: an orientation. Am J Epidemiol. 2003;157:364-75.

26. Altman DG. Statistics in medical journals: developments in the 1980s. Stat Med. 1991;10:1897-913.

27. Dubey J, Liddell S, Mattson D, Speer C, Howe D, Jenkins M. Characterization of the Oregon isolate of Neospora hughesi from a horse. J Parasitol. 2001;87:345-53.

28. El sector equino en cifras. http://www.mapama.gob.es/es/ganaderia/temas/ produccion-y-mercados-ganaderos/indicadoreseconomicossectorequino2015 tcm7-386080.pdf. Accessed 1 Feb 2017.

29. Alvarez-García G, Frey CF, Ortega-Mora LM, Schares G. A century of bovine besnoitiosis: an unknown disease re-emerging in Europe. Trends Parasitol. 2013;29:407-15.

30. Bennet SC. A peculiar equine sarcosporidium in the Anglo-Egyptian Sudan. Vet J. 1927:83:297-304

31. Bigalke RD. New concepts on the epidemiological features of bovine besnoitiosis as determined by laboratory and field investigations. Onderstepoort J Vet Res. 1968;35:3-137.

32. Bigalke RD. Studies on equine besnoitiosis. J Parasitol. 1970;56:29.

33. Gutiérrez-Expósito D, Ortega-Mora LM, Ara V, Marco I, Lavín S, Carvajal-Valilla J, Morales A, Alvarez-García G. Absence of antibodies specific to Besnoitia spp. in European sheep and goats from areas in Spain where bovine besnoitiosis is endemic. Parasitol Res. 2017;116:445-8. 
34. Madubata C, Dunams-Morel DB, Elkin B, Oksanen A, Rosenthal BM. Evidence for a recent population bottleneck in an Apicomplexan parasite of caribou and reindeer, Besnoitia tarandi. Infect Genet Evol. 2012;12:1605-13.

35. Dubey JP, Sreekumar C, Donovan T, Rozmanec M, Rosenthal BM, Vianna MC, Davis WP, Belden JS. Redescription of Besnoitia bennetti (protozoa: Apicomplexa) from the donkey (Equus asinus). Int J Parasitol. 2005;35:659-72

36. Elsheikha HM, Mansfield LS, Morsy GH. Studies on besnoitiosis bennetti in miniature donkeys. J Egypt Soc Parasitol. 2008;38:171-84.

37. Van Heerden J, Els HJ, Raubenheimer EJ, Williams JH. Besnoitiosis in a horse J S Afr Vet Assoc. 1993;64:92-5.

38. Pitel P, Lindsay D, Caure S, Romand S, Pronost S, Gargala G, Mitchell S, Hary C, Thulliez P, Fortier G. Reactivity against Sarcocystis neurona and Neospora by serum antibodies in healthy French horses from two farms with previous equine protozoal myeloencephalitis-like cases. Vet Parasitol. 2003;111:1-7.

39. Jakubek E, Lundén A, Uggla A. Seroprevalences of Toxoplasma gondii and Neospora sp. infections in Swedish horses. Vet Parasitol. 2006;138:194-9.

40. Machačová T, Ajzenberg D, Žákovská A, Sedlák K, Bártová E. Toxoplasma gondii and Neospora caninum in wild small mammals: seroprevalence, DNA detection and genotyping. Vet Parasitol. 2016;223:88-90.

41. Ferroglio E, Pasino M, Romano A, Grande D, Pregel P, Trisciuoglio A. Evidence of Neospora caninum DNA in wild rodents. Vet Parasitol. 2007;148:346-9.

42. Medina-Esparza L, Macías L, Ramos-Parra M, Morales-Salinas E, Quezada T, Cruz-Vázquez C. Frequency of infection by Neospora caninum in wild rodents associated with dairy farms in Aguascalientes, Mexico. Vet Parasitol. 2013;191:11-4

43. Antonello AM, Pivoto FL, Camillo G, Braunig P, Sangioni LA, Pompermayer E, Vogel FSF. The importance of vertical transmission of Neospora spp. in naturally infected horses. Vet Parasitol. 2012;187:367-70.

44. Pusterla N, Mackie S, Packham A, Conrad PA. Serological investigation of transplacental infection with Neospora hughesi and Sarcocystis neurona in broodmares. Vet J. 2014;202:649-50

45. Pitel P, Pronost S, Gargala G, Anrioud D, Toquet M, Foucher N, Collobert-Laugier C, Fortier G, Ballet J. Detection of Sarcocystis neurone antibodies in French horses with neurological signs. Int J Parasitol. 2002:32:481-5.

46. Arias M, Yeargan M, Francisco I, Dangoudoubiyam S, Becerra P, Francisco R, Sánchez-Andrade R, Paz-Silva A, Howe DK. Exposure to Sarcocystis spp. in horses from Spain determined by western blot analysis using Sarcocystis neurona merozoites as heterologous antigen. Vet Parasitol. 2012;185:301-4.

47. Dubey JP, Hattel AL, Lindsay DS, Topper MJ. Neonatal Neospora caninum infection in dogs: isolation of the causative agent and experimental transmission. J Am Vet Med Assoc. 1988;193:1259-63.

\section{Submit your next manuscript to BioMed Central and we will help you at every step:}

- We accept pre-submission inquiries

- Our selector tool helps you to find the most relevant journal

- We provide round the clock customer support

- Convenient online submission

- Thorough peer review

- Inclusion in PubMed and all major indexing services

- Maximum visibility for your research

Submit your manuscript at www.biomedcentral.com/submit
Biomed Central 